This is an electronic version of an article published in: Baich, Tina, Nora Dethloff, and Brian Miller. 2015. "Unlocking the Interlibrary Loan Code for the United States." Journal of Interlibrary Loan, Document Delivery, \& Electronic Reserve. 25, no 3-5: 75-88, http://dx.doi.org/10.1080/1072303X.2016.1254702. (2016 Great Lakes Resource Sharing Conference proceedings issue). Journal of Interlibrary Loan, Document Delivery, \& Electronic Reserve is available online at: http://www.tandfonline.com/toc/wild20/current

\title{
Unlocking the Interlibrary Loan Code for the United States
}

\section{Running head: U.S. ILL Code}

Tina Baich, IUPUI University Library

Nora Dethloff, University of Houston

Brian Miller, The Ohio State University

\section{Acknowledgements}

The work described in this article could not have been completed without the efforts of the entire ALA RUSA STARS Codes, Guidelines, and Technical Standards Committee, including Tina Baich, John Brunswick, Nora Dethloff, Margaret Ellingson, Denise Forro, Sue Kaler, Ryan Litsey, Candice Townsend, and, of course, our amazing Committee Chair, Brian Miller. 


\section{Unlocking the Interlibrary Loan Code for the United States}

\section{Running head: U.S. ILL Code}

\section{Abstract}

A newly revised Interlibrary Loan Code for the United States was approved in 2016, the $100^{\text {th }}$ anniversary of its first appearance. This article outlines the two-year, iterative revision process undertaken by the ALA RUSA STARS Codes, Guidelines, and Technical Standards Committee, including the results of two public surveys and significant changes to the Interlibrary Loan Code for the United States. The authors hope to provide a template for future revisions and share the process with the entire interlibrary loan community.

\section{Introduction}

The Interlibrary Loan Code for the United States (ILL Code) has reached an important milestone - its $100^{\text {th }}$ anniversary. The first interlibrary loan (ILL) code, called the Code of Practice for Interlibrary Loans, was developed by the American Library Association (ALA) Committee on Coordination in 1916 and approved by ALA on June 23, 1917 (“Midwinter meeting," 1917, p. 27; Bowker, 1917, p. 328). Since then it has undergone eight revisions, the most recent of which was approved January 11, 2016. Responsibility for the code transitioned to the Association of College \& Research Libraries (ACRL) for the earliest revisions and then to the Reference \& User Services Association (RUSA) and its precursors. After RUSA's Sharing \& Transforming Access to Resources Section (STARS) was formed in 2004, it assumed responsibility for the ILL Code and conducted the 2008 and 2016 revisions. Per current RUSA guidelines, the Interlibrary Loan Code for the United States is to be reviewed and revised every seven years. Additional information about current RUSA Standards \& Guidelines requirements can be found in Chapter Four of the RUSA Guide to Policies and Procedures.

The ILL Code establishes principles that facilitate the interlibrary loan process and regulates the exchange of materials between libraries in the US (ILL Code, 2016). Transactions outside the US are 
regulated by IFLA's International Resource Sharing and Document Delivery: Principles and Guidelines for Procedure. The ILL Code is divided into responsibilities of the requesting library and those of the supplying library with many of the points in each section paralleling each other. Topics include policies, requesting, payment, copyright, use restrictions, and loss or damage, among others. First introduced in 2001, the Interlibrary Loan Code for the United States Explanatory Supplement (Supplement) provides greater detail, background, and references for each point within the ILL Code. These documents combined are a valuable resource, especially for those relatively new to the practice of interlibrary loan.

All libraries in the US, regardless of type or size, are expected to voluntarily adhere to the ILL Code. There is no enforcement by an oversight body, but supplying libraries can suspend service to any requesting library that fails to comply with the ILL Code's provisions. However, the national ILL Code does not override any individual, consortial, regional, or state codes or agreements that may exist whether they are more liberal or prescriptive than the national code.

\section{Revising the Code}

The STARS Codes, Guidelines, and Technical Standards Committee (Committee) is formally charged with maintaining the ILL Code. The process for the 2016 revision began in January 2014, with the setting up of an online workspace, establishment of group norms and meeting times, and the creation of working documents. The Committee used a series of drafts in Google Drive to enable realtime commenting and editing on the text. Monthly conference calls allowed the Committee members to discuss the documents and proposed changes.

As a first step in the revision process, the Committee identified other guidelines and documents referenced in the ILL Code or the Supplement. The 2008 Supplement referenced a number of ALA guidelines dealing with specific formats, including microforms, magnetic tape, and audiovisual materials. These guidelines needed to be checked to ensure that they remained relevant and had not been superseded or sunsetted. Tina Baich, member of the Committee, reached out to the co-chairs of the 
Association for Library Collections and Technical Services (ALCTS) Preservation and Reformatting Section (PARS) to check the status of several ALCTS guidelines referenced in the Supplement. After discussion with PARS, references to the ALCTS documents were removed from the revised Supplement in order to allow PARS time for review. Brian Miller, Chair of the Committee, contacted the chair of the ALA Video Roundtable to determine the status of the Guidelines for the Interlibrary Loan of Audiovisual Formats (1998) referenced in the Supplement. As a result of this discussion, the Video Roundtable agreed that ILL of AV materials should be covered by the ILL Code, and not by a separate document. To ensure that the special circumstances surrounding the loan of AV materials were properly addressed in the revised code, feedback from the Video Roundtable was actively sought during the initial survey phase of the revision process.

In the summer of 2014 the Committee began in earnest the nuts and bolts process of revision. Each member was asked to carefully read both the ILL Code and Supplement and mark areas of confusion, concern, or areas in which technology or prevailing practices were changing. During monthly, two-hour conference calls, the Committee discussed each section of the ILL Code, point by point. Concerns or suggested changes brought by any member of the Committee were discussed by the entire group. These discussions helped the Committee to identify areas of the ILL Code and Supplement where practice was changing, or where clarification was needed. All meeting minutes, including decisions reached and action items to be completed, were saved in the Committee's online community space in ALA Connect.

During this time, the Committee was also developing a survey for distribution to the resource sharing community. Both the Committee and STARS leadership felt it was imperative to get feedback on the existing document before making any changes. Survey questions were formed based on the Committee's conversations, and on the parts of the code that were marked for possible revision. In the autumn of 2014 , this first survey was finalized and distributed to the resource sharing community. While 
waiting for the results, the Committee continued with in-depth examination and discussion of the ILL Code.

In November 2014 the survey results were used to mark areas of the code for possible change. The Committee discussed each comment received through the survey and considered how best to address any concerns raised, making revisions as appropriate. The survey results were especially useful in revealing areas of divided opinion, and the Committee discussed these issues at length. Throughout the winter of 2015 , intensive reading continued and additional revisions were made.

Group discussions and editing of the ILL Code and Supplement wrapped up in March 2015. The Committee then looked over the ALA ILL Request Form, and made some modifications to simplify the form and bring it up to date. Rough drafts of the revised ILL Code, Supplement, and ALA ILL Request Form were completed and reviewed by the Committee in April 2015. Per RUSA requirements, the draft documents were then sent to the STARS Executive Committee for approval, and then to the RUSA Standards and Guidelines Committee. During this approval process minor changes to the documents were suggested. These changes were incorporated and second drafts completed in June 2015.

Before the documents were finalized, the Committee issued a call for public comment on the revised ILL Code. A second survey was created for distribution with the draft documents. In September 2015 the documents were made available for public comment via a public post in ALA Connect. In September and October, multiple announcements directing practitioners to the drafts and providing a link to the survey were distributed via professional email discussion lists. An email address dedicated to feedback on the revisions was also made available for those who did not wish to take the full survey but wanted to provide commentary. Based on the feedback received from this comment period, final edits to the documents were made in December 2015.

Finally, according to RUSA procedures, the final documents were submitted to the RUSA Standards and Guidelines Committee, the STARS Executive Committee, and then the RUSA Board of 
Directors. The documents were approved at all levels, and formally went into effect on January 11, 2016.

\section{Community Feedback}

October 2014 Survey

As previously noted, the Committee developed a survey to gather feedback on the existing ILL Code. The survey was distributed via the ILL-L, WorkflowToolkit-L, and STARS-L email discussion lists on October 1, 2014. It was also circulated to ALA Video Roundtable members in order to retire the Roundtable's Guidelines for the Interlibrary Loan of Audiovisual Formats (1998) by integrating any special needs into the ILL Code. The community was asked to complete the survey by October 31, 2014. The survey requested demographic information from the 65 respondents (see Figures 1-3) and allowed them to propose revisions to the ILL Code and its Supplement in an open-ended format. The Committee reviewed and discussed each comment received. Through this review of the responses, themes were identified regarding proposed revisions to the responsibilities of the requesting and supplying libraries.

Figure 1. Respondents by Type of Library

Figure 2. Percentage of work time spent doing or managing resource sharing/interlibrary loan

\section{Figure 3. Number of years involved in resource sharing/interlibrary loan}

Requesting Library

The greatest number of comments related to the use of ILL as a method for obtaining a physical item for group or classroom use. Respondents commenting in this area fell into two distinct camps: (1) ILL items are only for the use of a single individual and (2) any use beyond that of a single individual 
must be communicated to the supplying library with the request so that potential lenders can make an informed decision regarding lending.

Several themes emerged around the proper handling and processing of materials. First, there were a variety of comments suggesting a stronger emphasis on proper and secure packaging of materials to prevent loss or damage. Respondents also seemed to be very much against the use of staples. Second, there were strong statements both for and against the use of removable labels on borrowed books. In the end, the Committee chose to prohibit the use of such labels on borrowed materials in the Supplement, but supplying libraries are still free to use adhesives on their own materials. Finally, respondents gave a variety of suggestions on the topic of renewals from who should initiate them to when they should be allowed relative to the due date.

The final theme that emerged around the responsibilities of the requesting library dealt with copyright and, more specifically, the Commission on New Technological Uses of Copyrighted Works (CONTU) guidelines. Some respondents expressed the belief that libraries should not be obligated under the ILL Code to comply with CONTU guidelines for every request made as CONTU is not law. They suggested that libraries should have the flexibility to balance and apply U.S. copyright law's fair use provision and the CONTU guidelines on a case-by-case basis.

\section{Supplying Library}

The major themes that emerged around the responsibilities of the supplying library can be grouped into two categories, handling and processing of materials and communication. As in the responsibilities of the requesting library, the Committee received comments regarding the use of secure packaging to prevent loss and/or damage. Similarly, respondents stated that supplying libraries should be highly discouraged from sending via fax due to the poor quality or via mail due to longer turnaround time, unless prohibited from using electronic delivery by license terms. 
The three remaining themes can be loosely categorized as communication issues. First, requesting libraries need to recognize the communicated needs of the requesting library regarding shipping address so that returnables arrive promptly to the correct location. Second, several respondents wanted the Committee to reconsider the meaning of no response to a renewal request or to define prompt processing of renewals. Respondents also wanted no renewals clearly marked on the paperwork sent with an item. These suggestions regarding renewals all attempt to address a lack of communication on the part of the supplying library. Finally, there were a number of general comments regarding communication between supplying and requesting library, including special use or delivery restrictions before shipping; notification of service suspension for violation of Code; and including specific identifying information for requests in overdue, recall, and billing notifications.

\section{Due Date Definition}

In addition to general revisions to the responsibilities, the Committee was debating whether to continue with the due date definition in the 2008 version of the ILL Code or return to the previous definition of due date used prior to 1994, which would be a major change. For this reason, there was a survey question specifically dealing with this issue. Respondents were asked which of the following due date definitions they preferred.

Previous due date definition: Prior to 1994, ILL Code addressed 'duration of the loan' and specified the time at which the item may remain at the borrowing library, disregarding time spent in transit. In this scenario, the due date for the borrowing library and user are the same as specified by the supplying library. Supplier can include a grace period to take into account return shipping time.

Current due date definition: Date the material is due to be checked in at supplying library. Receiving library must subtract return shipping time from supplier's due date and set earlier due date for their user. 
The majority of respondents preferred the "previous" definition as seen in Figure 4. Comments in support of reverting to the previous definition fell into three categories.

1. Return delivery times vary per item depending on lender distance and are hard to predict.

2. Gives patron maximum time with the item, especially if the loan period is short or there is a delay in arrival/pick-up.

3. Don't want to track two due dates (i.e. the date you give your patron and the date by which the item has to be back at the supplying library). One due date is easier for ILL request management systems.

Of those in favor of the "current" definition, comments revolved around the following themes.

1. Encourages long loan periods with sufficient use and return time.

2. Overdue notices are sent from circulation system (not ILL system) on same schedule as for local patrons.

3. The previous definition "encourages laxness in ILL staff concerning returns."

Figure 4. Preference between previous and current definition of due date in 2014 survey September-November 2015 Survey

The Committee made the final draft documents available for public comment and deployed a second survey to solicit public comment during a two-month period in the autumn of 2015. There were 142 responses recorded, including both complete and partial responses. While many of the comments received dealt with grammar and punctuation, the Committee also received some feedback regarding the content of the ILL Code. Most significantly, feedback on redefining the new due date as the date by which the material is due back to the requesting library was overwhelmingly positive by a ratio of nearly 6 to 1 (Figure 5). 
Figure 5. Preference between previous and current definition of due date in 2015 survey

Other comments that led to further revisions of the ILL Code included criticism of defining the purpose of ILL for an individual's "relatively short term use." Some felt that this discouraged generous loan periods, which was contrary to the intent of the Committee. There was also criticism of allowing the use of ILL for locally checked out items. Libraries were concerned they would be required to give patrons the ability to place ILL requests for such items, so the statement was revised to clarify this practice as a possibility rather than a requirement.

Survey respondents represented a variety of library types (Figure 6) and levels of experience (Figure 7).

Figure 6. Respondents by Type of Library

\section{Figure 7. Number of years involved in resource sharing/interlibrary loan}

\section{Summary of Significant Changes}

Significant changes include revisions intended to bring the ILL Code and Supplement up to date with changes in prevailing practice, changes intended to encourage communication between libraries, and changes to make the ILL Code itself more readable and easier to apply. Many of the changes were a direct result of feedback received from the ILL community.

General Changes:

- Although there are still two separate web pages for the ILL Code and the Supplement, the content has also been merged into one printable PDF for easier reading and consultation.

- A newly revised ALA ILL Request Form is also available. The new version is simpler, cleaner, and available as a fillable PDF. These revisions reflect changes in prevailing 
practice and advances in technology in the years since the form's last revision, and will make the request form easier to use for both requesting and supplying libraries.

- Section 2.0 of the ILL Code, "Purpose of Interlibrary Loan," has been revised to define ILL as "primarily intended to provide a requesting individual" a loan or copy of needed materials. The same section of the Supplement now states that "when policy and circumstances warrant, interlibrary loan may also be used to obtain materials that are owned by the local library but which are not available because they are damaged, missing, or checked out."

- International ILL is now actively encouraged in section 3.0 of the ILL Code, although these transactions are still governed by IFLA's International Resource Sharing and Document Delivery: Principles and Guidelines for Procedure (2009).

Changes for Requesting Libraries:

- Section 4.1 of the Supplement no longer requires that a paper copy of the requesting libraries' borrowing policies be made available.

- In response to concerns about patron privacy and changes to commonly used software, section 4.2 of the Supplement now discourages the sharing of user names on ILL requests.

- Section 4.4 of both the Code and the Supplement require the requesting library to communicate any special requirements related to a request, such as an alternate shipping address, or if an item is needed for a special purpose such as for course reserves or in-classroom use.

- References to CONTU were removed from section 4.8 of the Code, allowing libraries to make their own decisions about how to best comply with Copyright Law. CONTU is 
instead referenced in section 4.8 of the Supplement as a guideline that should be taken into consideration.

- Section 4.9 of the Supplement now explicitly prohibits the use of adhesive labels or tape on borrowed materials.

- A new section, 4.10, was created in both the Code and the Supplement to consolidate billing and payment information. This section of the Code states that requesting libraries must "pay promptly" any fees, and the same section of the Supplement defines "promptly" as no later than six months from the billing date.

- Section 4.12 of the Code now defines "due date" as the "date by which the material is due to be checked in at the requesting library for return to the supplying library." The same section of the Supplement encourages requesting libraries to return "materials to the supplying library promptly following check in."

- Reflecting a change in prevailing technology, renewals can now be requested after the due date. However, section 4.13 of the Code still stipulates that renewals should be requested "before the item is due whenever possible."

- New language in section 4.15 of the Supplement "strongly" discourages the use of staples on packages.

- References to outdated and retired guidelines for magnetic tape, microforms, and AV were removed from several sections of the Supplement. For rare or unique materials, requesting libraries should still consult the Guidelines for Interlibrary and Exhibition Loan of Special Collections Materials.

Changes for Supplying Libraries:

- Generous loan periods are now encouraged by section 5.1 of the Supplement. 
- Section 5.3 of both the Code and Supplement encourage libraries to fulfill requests without charging fees.

- Section 5.4 of the Code now asks supplying libraries to consider filling requests regardless of the material's format or the collection in which it is housed.

- ILL staff are now encouraged by section 5.4 of the Supplement to "work with those negotiating licenses for electronic resources to include favorable terms for interlibrary loan."

- When supplying a loan instead of a copy, section 5.4 of the Supplement now explicitly requires supplying libraries to "contact the requesting library to secure their permission first."

- Communication is again encouraged in section 5.5 of the supplement, which stipulates that requesting libraries should negotiate any special requirements, such as loan terms or use restrictions, before updating the request.

- "Due date" is now defined by section 5.7 as "the date the material is due to be checked in at the requesting library for return to the supplying library." In order to allow for return shipping time, the same section of the Supplement stipulates that supplying libraries should implement a grace period before sending overdue notices.

- Section 5.11 of the Code now indicates that supplying libraries must comply with both copyright law and local licenses. (The 2008 Code only required that libraries "be aware of" license agreements.)

- A new section of the Supplement, 5.11, addresses the quality of reproductions when supplying copies. Scans should closely reproduce the original "in appearance, legibility, and completeness with appropriate attention paid to image color and clarity, margins, page orientation, and any accompanying references, plates, or appendices." 


\section{Outreach Activities}

Since the approval of the ILL Code revision in January 2016, the Committee worked diligently to get the word out through a variety of promotional mechanisms. Brian Miller distributed announcements on ILL-related email discussion lists and social media in mid-February 2016. In the spring and summer, committee members gave presentations on the new ILL Code to several gatherings of resource sharing practitioners around the country, including at the ILLiad International Conference, Greater Western Library Alliance Resource Sharing and Collection Development Joint Meeting, Association of College \& Research Libraries New England Annual Conference, Great Lakes Resource Sharing Conference, and ALA Annual Conference. A list of the Top Ten Changes to the ILL Code and Supplement was distributed to attendees at ALA Annual and via email to multiple ILL discussion lists. Committee members also offered a free webinar on the newly revised Code to the ILL community in July 2016 in partnership with OCLC. A recording of the webinar was then made freely available afterward. Finally, the ILL Code was published in the Summer 2016 issue of Reference \& User Services Quarterly (Committee, 2016) to inform the entire RUSA membership.

\section{Conclusion}

The ILL Code is a key guiding document for ILL practitioners and thus must be treated with great care and respect. Because every library engaged in resource sharing has a stake in the evolution and updating of the code, it was important to RUSA STARS and the STARS Codes, Guidelines, and Technical Standards Committee that the revision process be inclusive, iterative, and as transparent as possible. The participation of the ILL community was essential in maintaining both the usefulness and integrity of the ILL Code. This article is the culmination of several years' effort to engage resource sharing practitioners and stakeholders through polling, drafts, and public comment. It is the hope of the authors that documenting the process used in this revision process will provide insight into the revisions and why and how they were made. As we mark the $100^{\text {th }}$ anniversary of the ILL Code, the ILL community 
should also celebrate its ongoing commitment to collegial cooperation and resource sharing. The ILL Code will once again be due for revision in 2021 , and this article may also serve as a guide for the next iteration of the committee when they once again begin the process of updating this important document.

\section{References}

Bowker, R. R., et al. (1917). Proceedings June 21-27, 1917. Bulletin of the American Library Association 11(4), 314-355.

Guidelines for the Interlibrary Loan of Audiovisual Formats. (1998). Archived at: https://web.archive.org/web/20160621133933/http://www.ala.org/vrt/professionalresources/ vrtresources/interlibraryloan

International Resource Sharing and Document Delivery: Principles and Guidelines for Procedure. (2009). Retrieved from http://www.ifla.org/files/assets/docdel/documents/international-lending-en.pdf Interlibrary Loan Code for the United States. (2016). Retrieved from http://www.ala.org/rusa/resources/guidelines/interlibrary Interlibrary Loan Code for the United States Explanatory Supplement. (2016). Retrieved from http://www.ala.org/rusa/resources/guidelines/interlibraryloancode

Midwinter meeting of the council. (1917). Bulletin of the American Library Association 11(1), 1-30.

Reference \& User Services Association. (n.d.). Guide to Policies and Procedures. Retrieved from: http://www.ala.org/rusa/about/policies

STARS Codes, Guidelines, and Technical Standards Committee. (2016). From Committees of RUSA: Interlibrary Loan Code for the United States. Reference \& User Services Quarterly 55(4), 306-307. 


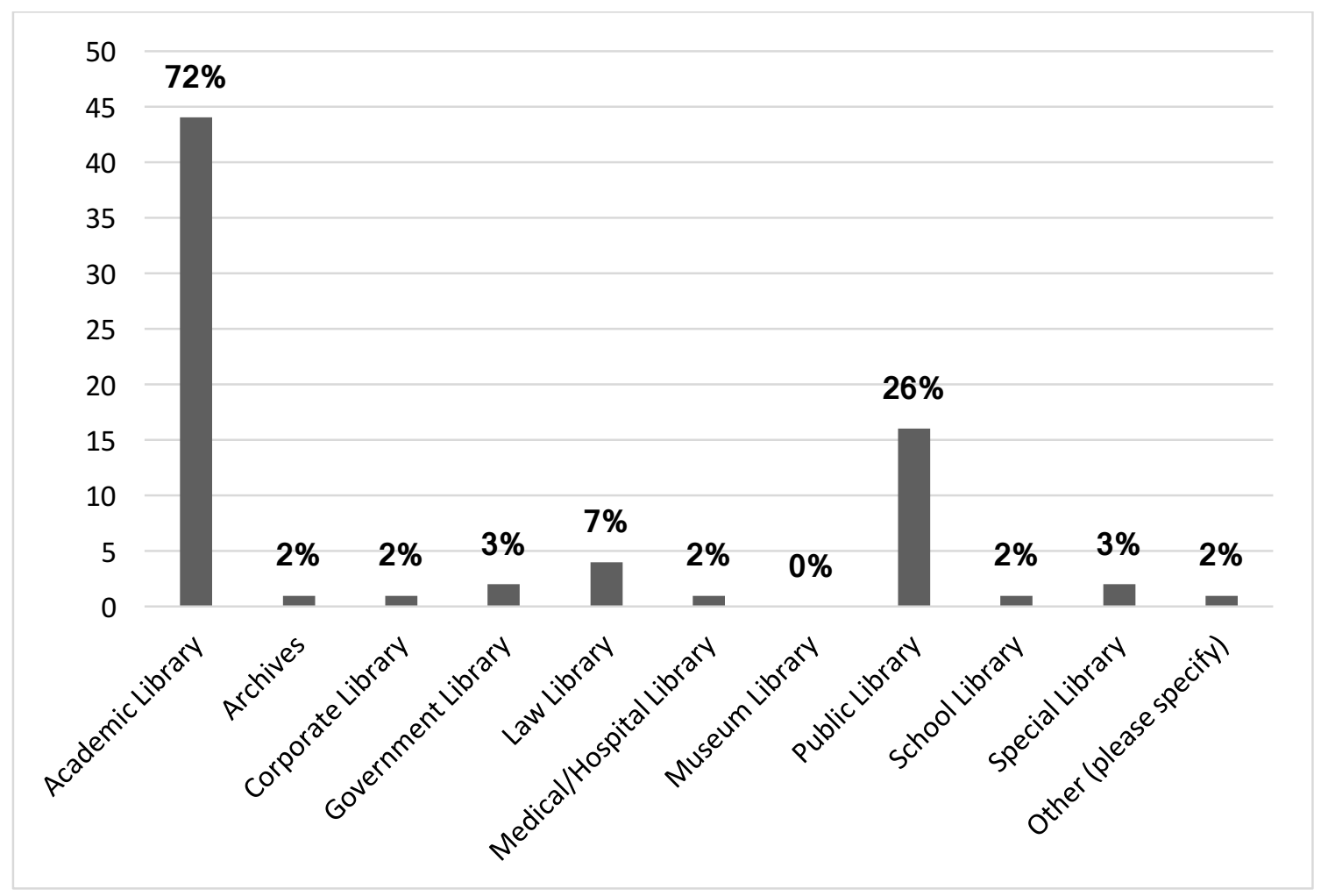

Figure 1. Respondents by Type of Library (61 total respondents) 


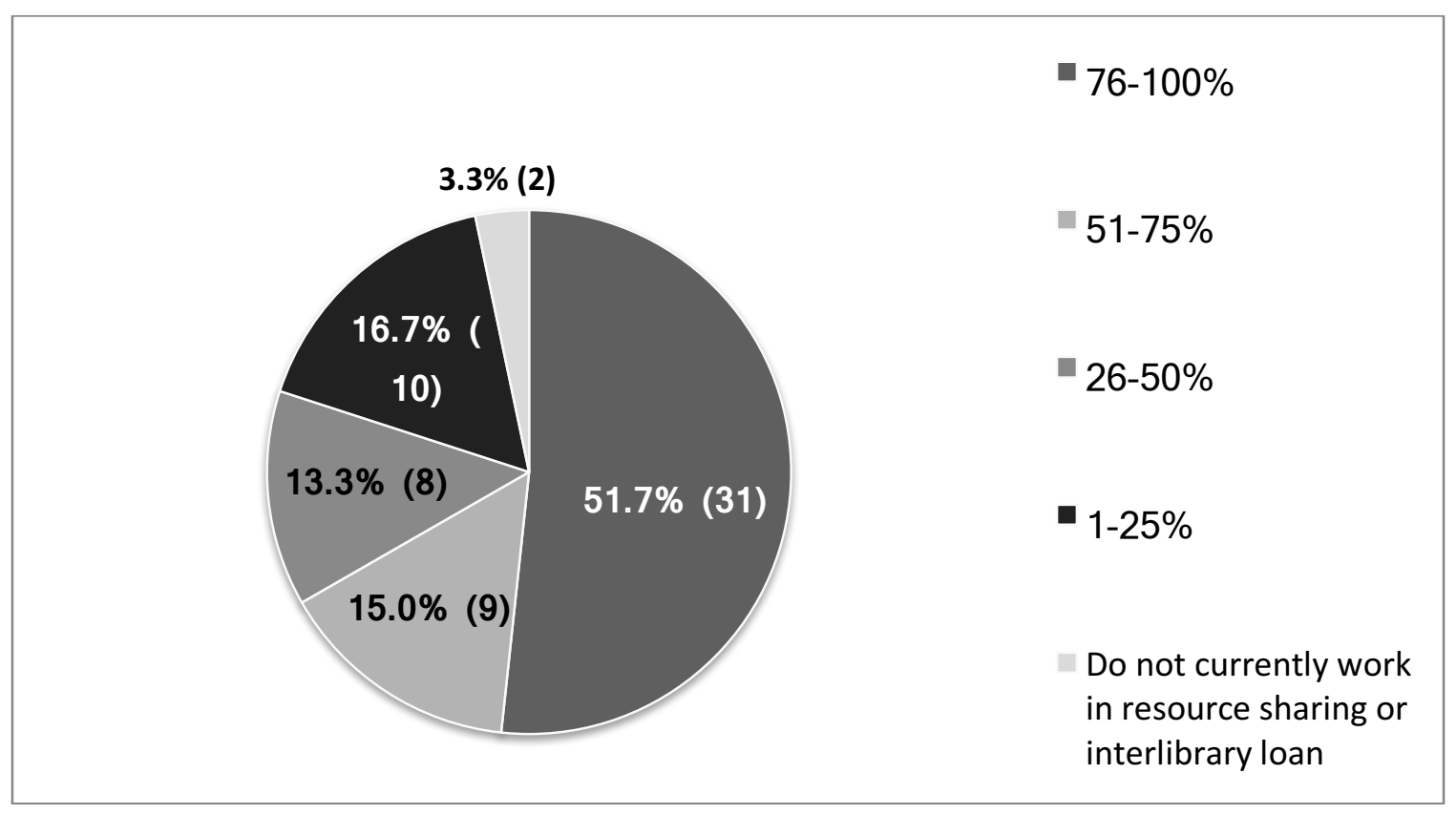

Figure 2. Percentage of work time spent doing or managing resource sharing/interlibrary loan (60 respondents) 


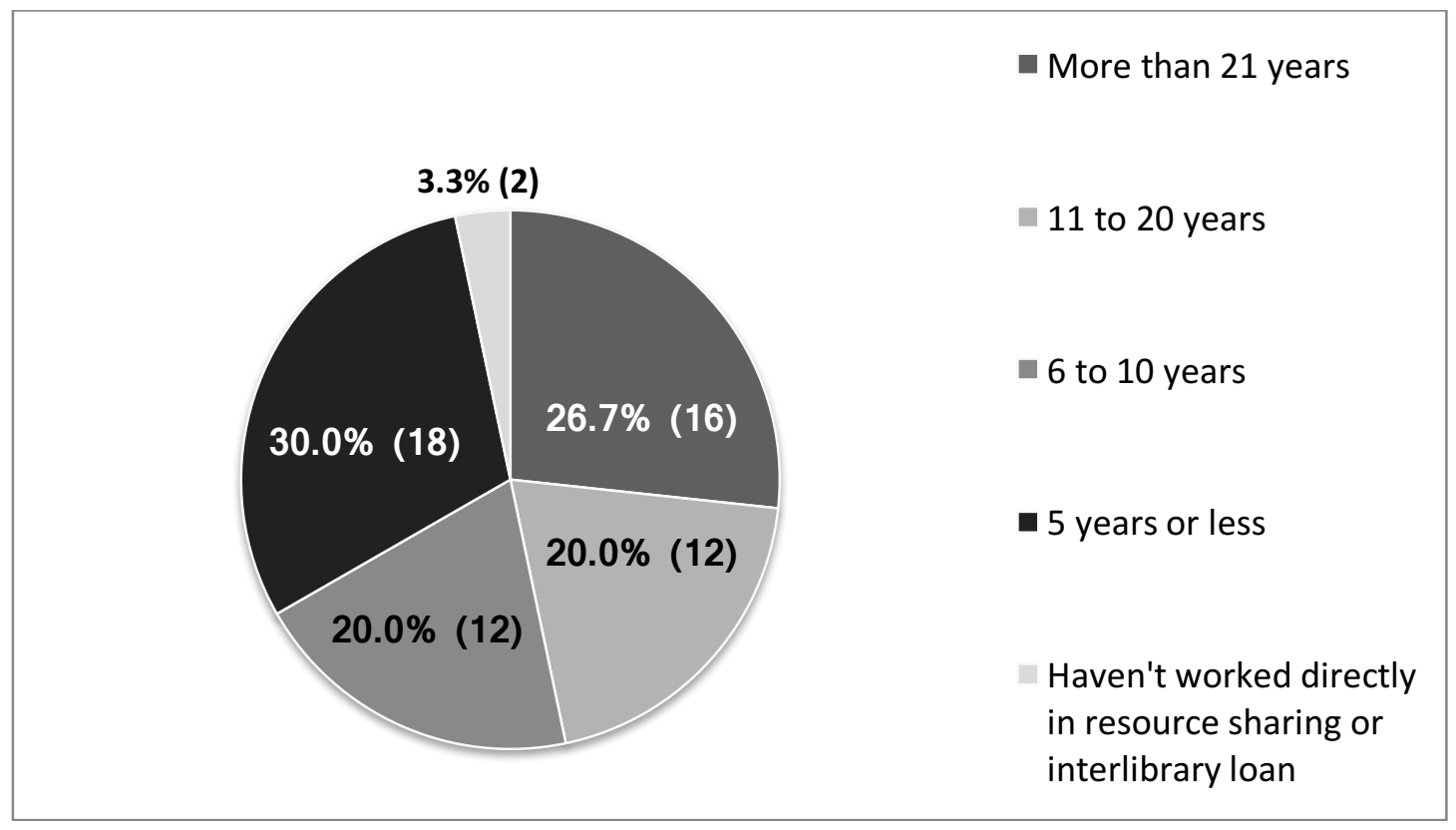

Figure 3. Number of years involved in resource sharing/interlibrary loan (60 respondents) 


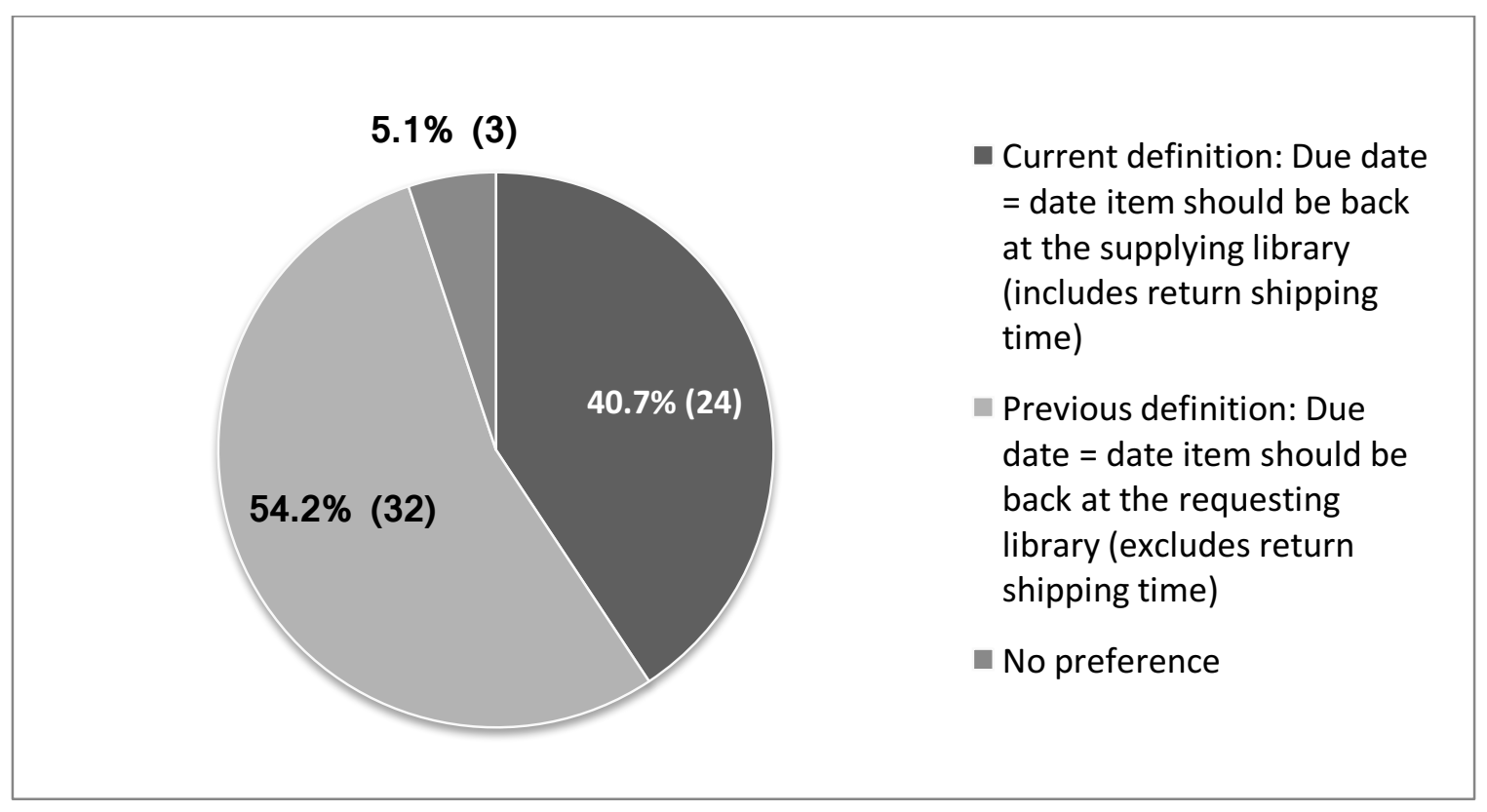

Figure 4. Preference between previous and current definition of due date in 2014 survey (59 respondents) 


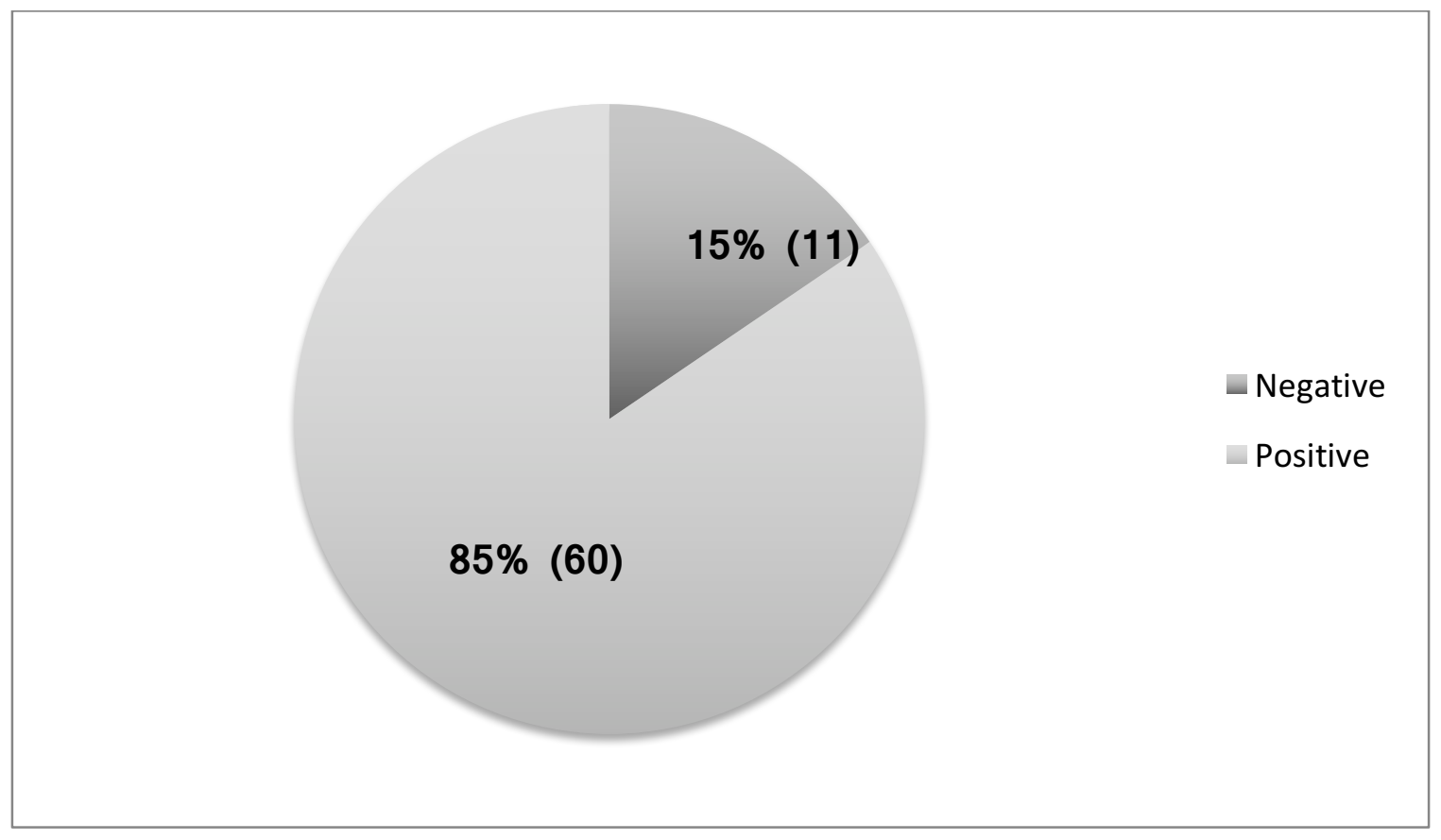

Figure 5. Positive versus negative feedback regarding redefining the due date to be "the date by which the item is due to be checked in at the requesting library for return to the supplying library" (71 responses) 


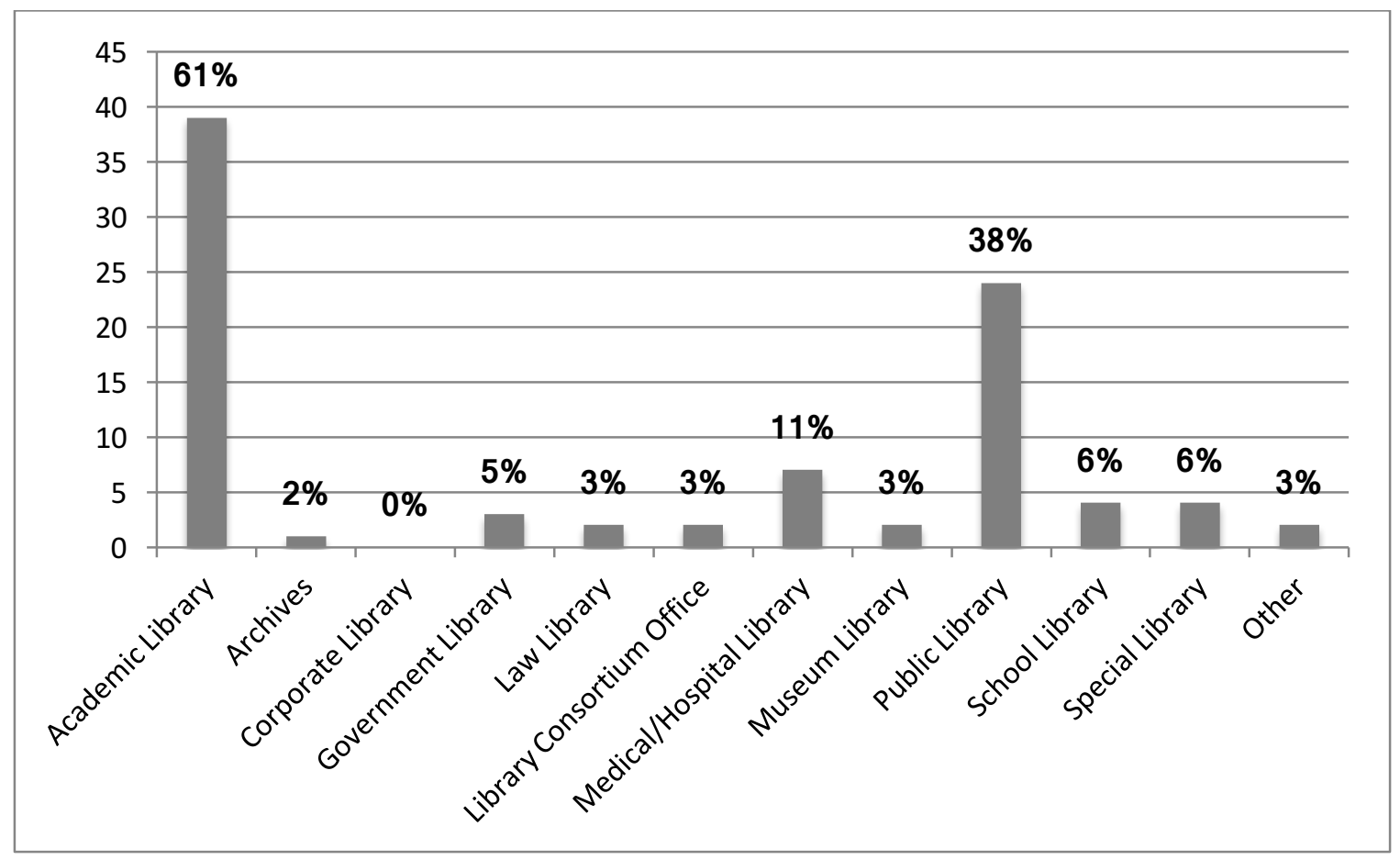

Figure 6. Respondents by Type of Library (64 respondents) 


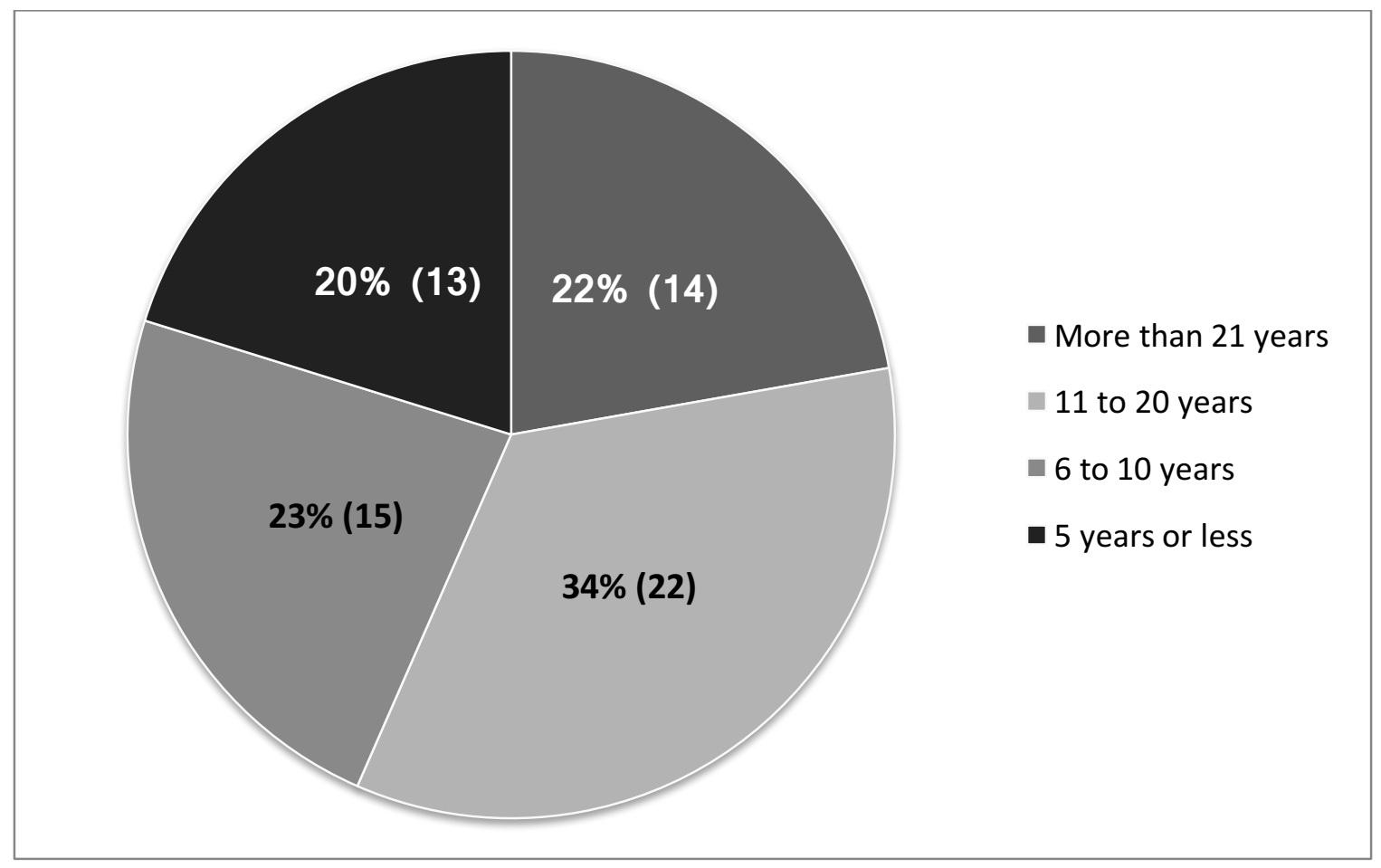

Figure 7. Number of years involved in resource sharing/interlibrary loan (64 respondents) 